(C) 2016 IEEE. Personal use of this material is permitted. Permission from IEEE must be obtained for all other uses, in any current or future media, including reprinting/republishing this material for advertising or promotional purposes, creating new collective works, for resale or redistribution to servers or lists, or reuse of any copyrighted component of this work in other works. 


\section{Populating Contents of the Saudi eLearning Objects Repository "Maknaz" from Information Technology $\&$ Knowledge Management Perspective}

\author{
Abdullah M. Alammari \\ School of Systems, Management and Leadership \\ Faculty of Engineering and Information Technology \\ University of Technology Sydney \\ Sydney, Australia and \\ Faculty of Education, Umm Al-Qura University \\ Makkah, Saudi Arabia \\ a.alammari@student.uts.edu.au
}

\author{
Daniel Chandran \\ School of Systems, Management and Leadership \\ Faculty of Engineering and Information Technology \\ University of Technology Sydney \\ Sydney, Australia \\ Daniel.Chandran@uts.edu.au
}

\begin{abstract}
E-Learning is an important tool for current learning and teaching processes. Learning Objects Repository (LOR) has been seen as a key factor in eLearning and knowledge management environment. Universities in Saudi Arabia have prioritized implementing eLearning in their development plans. However, current learning and teaching process in higher education in Saudi Arabia is still mostly traditional. Educational and information technologies adoption is slow due to the lack of awareness about the importance of collaborative learning that is mainly based on LORs knowledge and technical skills that educators and learners should have. There is a need to study the possible technical tools and approaches that can direct eLearning practices in Saudi Arabia to embrace the initiative of the Saudi National Learning Objects Repository "Maknaz" in order to collaboratively populate and digitalize its knowledge contents. Due to the slow adoption of technologies and knowledge management systems in Saudi higher education, it is important to analyze the academics and students' acceptance toward current eLearning environment implemented so far. This paper investigates what efforts have been made so far to implement eLearning and LORs technologies in Saudi Arabia; and suggests what is required from participants in the higher educational institutions to link these technologies to education and pedagogy practices based on an integrated knowledge management system with eLearning to creatively create and exchange new knowledge localized in LORs.
\end{abstract}

Keywords- Information Technology; Learning Objects Repository; Learning Objects; Knowledge Management; eLearning, Saudi Higher Education.

\section{I.INTRODUCTION}

The recent revolution in information technology has urged educational institutions to provide electronic learning (eLearning). E-Learning is defined as the delivery process of training and educational courses over the internet or via electronic devices [1]. Although e-learning has some challenges countering its implementation, it seems to be a general acknowledgment in the education sector for the effectiveness that can be brought by the adoption of online learning's technological tools. In that respect, the provision of education with the blended method has achieved all education stakeholders' satisfaction. Blended learning is the most effective method because it can meet the new generation's needs as well as it keeps the benefits of the traditional learning [2]. The growth of eLearning delivery will be accelerated due to the advancement in hardware, software and open source technology and is expected to reach $\$ 49.9$ billion by 2014 [3]. Teachers and students' attitudes against the new movement toward electronic learning should be taken into consideration when introducing eLearning.

Different practices in the eLearning environment have supported the eLearning effectiveness. Practices in electronic learning are characterized based on instructional design. In other words, professionals working in eLearning systems mostly prefer to deliver eLearning in scenarios and tutorialbased learning practice. Therefore, delivering and measuring knowledge to students will be easily tailored and adjusted to the current students' preferences and abilities. This feature is a key factor of eLearning allowing learners and teachers to work freely and efficiently as it gives them privileges of personalization and flexibility in learning.

Knowledge Management is the process of knowledge capturing and communicating which organizations undertake to achieve their objectives and thus increase the overall performance [4]. Knowledge Management (KM) has been associated with the social computing technologies, collaborative interactive online learning communities [5]. Both disciplines Knowledge Management and eLearning deal with the knowledge seeking, communicating and reusing [6].

Learning Object Repositories (LORs) is defined as the container for stored learning digital resources and contents that are offered to be open and available for reuse amongst all eLearning communities' participants. LOR has recently emerged due to the need for creating, filtering, sharing and reusing of digitalized educational resources within eLearning communities [7].

Saudi Ministry of Higher Education (MOHE) has launched a national LOR project called 'Maknaz' which aims to serve the strategic plans towards the enrichments in learning 
resources and knowledge growth. This achievement was announced as "The Saudi National Center for eLearning (NCEL) and eXact learning solutions, formerly known as Giunti Labs, have revealed details of the Saudi Arabia's Maknaz - or 'Treasure Chest' - Project, the largest learning content digital marketplace implementation in the Arabic world" [8]. Particularly, 'Maknaz' has been established and equipped with Learning Contents Management Systems (LCMS) to advance the eLearning environment in all Saudi universities as it will facilitate a wider access to national and international repositories networks [9]. It advantages the eLearning communities through the storage and reusability of educational contents amongst all participants who are encouraged to adapt and constantly add new electronic learning objects into 'Maknaz' [10].

Despite the fact that eLearning can introduce higher interactivity and productivity in the education field all over the world for teaching and learning, it may be difficult to some extent to be actively adopted in Saudi higher education. Generally, the difficulty in adopting eLearning is not with the style of learning, but it is more challenging as universities need their system of teaching to be restructured; also the new infrastructure of eLearning requires additional resources which may be lacked in such organizations [2]. Importantly, there is a noticeable unawareness about eLearning LORs and the importance of knowledge management practices across all Saudi higher education levels. Furthermore, it requires qualified educators with IT skills to run the online learning tools effectively [11]. Such technical skills are clearly unavailable among the majority of faculty and students in Saudi higher education sector.

\section{II.PROBLEM STATEMENT}

There is a need to populate the Saudi national Learning Objects Repository 'Maknaz' with reusable digitalized content and learning electronic materials [10]. E-Learning communities lack an integrated eLearning LOR and knowledge management framework that leads to learning content creation, knowledge management practices and processes in an online learning approach. Also, there is noticeable unawareness about eLearning LORs by teachers and their students in Saudi universities. However, integrating knowledge management practices and techniques in eLearning can offer Saudi eLearning communities with knowledge content creating, filtering, sharing and reusing. Thus, the national LOR 'Maknaz' will be effectively populated with added digitalized knowledge contents constantly by all participants in eLearning environment.

\section{III.OVERVIEW OF EDUCATION IN SAUDI ARABIA}

Education efficiency improvement in Saudi Arabia has been the main concern of the Saudi government. With no doubt, it is significant to consider the current situation of learning and teaching processes in Saudi Arabia to understand the current learning levels. Analyzing the current educational practices can help to highlight challenges and obstacles that could be eliminated while executing new development plans.
Reference [11] noted that several factors challenging the education in developing countries also exist in Saudi Arabia:

- Learners memorize information they receive more than they think. Consequently, the memorized information will be lost neutrally since the thinking and analyzing techniques of creative learning to deliver new knowledge is absent.

- Lack of collaborative learning and teamwork or interactive education.

- Quantity of learning materials has greater priority than quality in the teaching process.

- Lack of efforts to update learning curriculum, methods, gears and the knowledge sharing processes amongst learners and teachers.

- Less awareness and interest from teachers and learners in adopting eLearning since users' encouragement to accept eLearning has not taken into consideration yet. Educators and leaners should be seen as the key elements (provider and receiver) in the eLearning knowledge creation and exchange process when applying new technology.

\section{IV.STUDY OBJECTIVES}

- To analyze the current situation of eLearning LORs acceptance in Saudi higher education.

- To highlight the problem that eLearning in Saudi Arabia faces with the absence of knowledge management framework based on LORs and technology skills among all parties involved in the education and pedagogy process.

- To provide the best practice framework solution to adopt and creatively populate the eLearning LORs in Saudi higher education "Maknaz" from IT and knowledge management perspective.

\section{V.STUDY SIGNIFICANCE}

This paper will add value to the research area since there is a need to develop a better environment of eLearning in Saudi universities. Saudi Arabia has a strong vision toward improving the educational and training sectors to advance the individual and organizational learners to deliver knowledge and skills required in the Saudi market. This is a clear commitment from Saudi government in developing human knowledge and learning infrastructure. There are numerous investments to adopt and build eLearning infrastructures in Saudi Arabia at university levels and organizational levels. However, the current adoption status of eLearning communities LORs in Saudi Arabia can be described as in [12] that "most local researchers have noted that technology and LORs use in the classroom is still the exception rather than the rule; and for those individuals and institutions that do use technology, adoption is still in the early stages".

Saudi LORs portal has been available since 2007 for education and research communities in order to offer beneficial 
knowledge and reusable/shareable learning materials for learners in Saudi Arabia. In fact, LORs platform in Saudi Arabia is confirmed by the manager of the Saudi National Center for eLearning (NCEL) that it has been launched to be the Knowledge Management Portal which can empower eLearning communities in Saudi higher education [13]. However, this LORs portal is quite new and greater research to develop its implementation and adoption is needed. This need was raised as that "room remains for Saudi Arabia to improve, and eventually master the digitalization of learning contents in repositories... Integrating the merits of existing high-calibre LOR platforms worldwide can help the country to keep up with the rapid e-learning transformation occurring globally. Prior to its production, execution, administration and maintenance, a comprehensive LOR framework encompassing everything from content/subject, target, syllabus and evaluation activities to an online learning approach must be formulated" [13].

\section{VI.RESULTS}

The result of this research is to provide the best practice framework solution to adopt and effectively populate eLearning LORs in Saudi higher education from IT and knowledge management perspective. Fig. 1, below represents the proposed model; incorporating knowledge management practices as referenced in a recent cited study in [7].

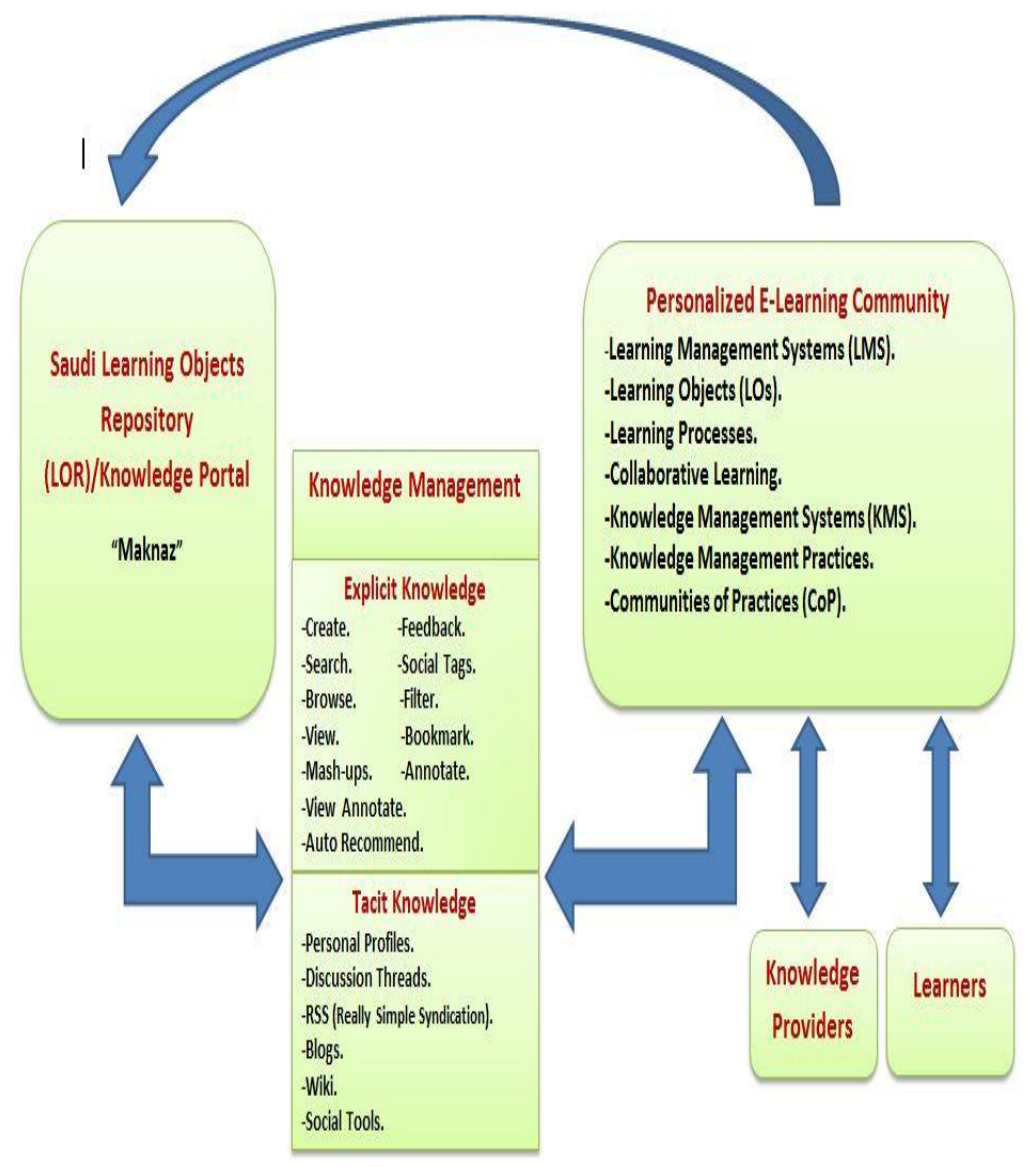

Fig. 1. An Integrated E-Learning LORs and KM Framework
The proposed model can illustrate the knowledge cycle within the integrated eLearning LORs and knowledge management environment when interaction between entities occurs. These entities are: Personalized eLearning Community, Explicit/Tacit Knowledge Management Tools, Saudi Learning Object Repository (LOR) 'Maknaz' and Knowledge Providers \& Receivers (Learners).

Reference [14] noted that Information Communication Technology (ICT) roles within higher education institutions and eLearning communities can be divided into three groups:

- Information Technology for knowledge codification and storage including different types of learning knowledge repositories and training tools.

- Communication Technology to support knowledge transferring regardless of its different formats, users' operating systems and their communication protocols.

- Collaborative Technology to enhance users' collaboration and to include knowledge maps as pointers to knowledge and information providers internally or externally of educational institutions.

Beside this and from Information Technology solutions perspective, our model suggests that the eLearning community in Saudi Arabia should be featured as Communities of Practices (CoPs) with collaborative learning processes; indeed Knowledge Management Systems (KMS) and KM Practices are proposed to be the key elements in this inclusion.

This model shows that knowledge or Learning Objects (LOs) are populated and constantly added into LOR 'Maknaz' when adopting and interacting $\mathrm{KM}$ practices by all entities within the eLearning community. Professional knowledge providers or educators and learners are significant components of the 'Maknaz's knowledge populating \& exchanging cycle.

Recent cited studies in [7] stated that Explicit Knowledge is captured through several added tools such as Create, Search, Browse, View, Filter, Mash-ups, Annotate, View Annotate, Bookmark, Auto Recommend, Feedback and Social Tags; whereas Tacit Knowledge is gained through Personal Profiles, Discussion Threads, RSS (Really Simple Syndication), Blogs, Wiki and Social Tools. Based on this, Explicit and Tacit knowledge in eLearning are gained by formal \& informal communication through IT and Internet social tools available in Web 2.0 technologies. Knowledge management practices are proposed to be adopted in Saudi eLearning communities to manage knowledge creation and flow between all participants who effectively will populate and reuse the eLearning contents of 'Maknaz' which can be considered here eventually as the Knowledge Assets Base.

\section{VII.OUTCOMES}

'Maknaz' serves as LOR or Knowledge Assets Base portal which offers the chance to customize and deploy the proposed eLearning \& Knowledge Management model in Saudi eLearning environment. The need for populating 'Maknaz' with learning objects and knowledge archives can be fulfilled when knowledge management practices and processes are adopted in the eLearning communities in Saudi Arabia. The 
fundamental goals of knowledge management in the proposed integrated model are learning knowledge creation and knowledge dissemination as the knowledge cycle can represent in the model.

In the proposed model all participants within the eLearning community in Saudi Arabia can benefit from knowledge management systems along with Community of Practices tools to generate, transfer, capture and communicate or share the learning knowledge contents within online community. Thus, created knowledge content is constantly added to 'Maknaz' to be reused by eLearning seekers and providers; and this leads to the potential goal that 'Maknaz' as a national Learning Objects Repository platform is hoped to achieve.

\section{VIII.CONCLUSION}

Implementing eLearning LOR in Saudi Arabia without strategic management system for eLearning is a drawback [15]. Thus, knowledge management practices for eLearning in Saudi Arabia should be implemented and adopted to enrich the current learning and teaching/training processes in Saudi Arabia. Importantly, integrating knowledge management and eLearning has been reported as a need in recent research and it can help to achieve the satisfactory level of the education outcome in Saudi Arabia since the Saudi government has prioritize the education and training projects in its annual strategic national development plans. Saudi Arabia's elearning market is forecast to reach at US $\$ 670$ million by 2014 , and its annual growth rate of approximately $33 \%$ in the 2010 2014 periods [10].

Integrated eLearning and knowledge management model based on learning flexibility and personalization can empower the Saudi eLearning communities' knowledge creation and dissemination. This proposed model can be ideal for new trends in online learning such as the Massive Online Open Source Courses (MOOC) in Saudi Arabia [15]. It is argued that future learning knowledge contents creation and exchange is an ongoing process by all participants involved in learning and training environment. Consequently, the massive learning knowledge contents within online learning communities cannot be effectively managed and reused without the adoption of knowledge management practices. This study proposes to develop a potential best practice eLearning and knowledge management model that can enrich the Saudi eLearning development. However, an advance research in this area is needed

\section{REFERENCES}

[1] Cooper, C., Taft, L.B. \& Thelen, M. 2004, 'Examining the role of technology in learning: An evaluation of online clinica conferencing', Journal of Professional Nursing, vol. 20, no. 3, pp. 160166

[2] Leal, J. 2009, "E-learning and Online Education: Implications for the Future of Law Enforcement Training", World Future Review, vol. 1, no. 3, pp. 22-28.

[3] Chandran, D. 2013, E-learning in Developing Countries: A Case Study, The 22nd IBIMA conference on Creating Global Competitive Economies: 2020 Vision Planning \& Implementation, Rome, Italy 13-14 November 2013 in Proceedings of the 22nd International Busines Information Management Association Conference (IBIMA), ed Khalid S. Soliman, IBMA Publishing, Norristown, PA USA.

[4] Chandani, A., Neeraja, B., \& Sreedevi, (2007). Knowledge management: An overview \& its impact on software industry. Information and Communication Technology in Electrical Sciences (ICTES 2007), 2007. ICTES. IET-UK International Conference on 1063-1068.

[5] Eger, L., \& Egerová, D. (2013). e-Learning trends in Central Europe: The case of the Czech Republic. Knowledge Management \& ELearning, 5(3), 375-387.

[6] Frank, M.S. \& Liebowitz, J. 2011, Knowledge management and elearning, Auerbach Publications, Boca Raton, FL.

[7] Sampson, D. G., \& Zervas, P. (2013). Learning object repositories as knowledge management systems. Knowledge Management \& $E$ Learning, 5(2), 117-136.

[8] Exact Learning Solutions, W. 2010. Maknaz Digital Marketplace Project | eXact learning solutions. [online] Available at: http://www.exact-learning.com/en/news/2010/12/01/maknaz-digitalmarketplace-project [Accessed: 6 Jan 2014].

[9] Exact Learning Solutions, W. 2010. NCEL | eXact learning solutions [online] Available at: http://www.exact-learning.com/en/ourclients/case-studies/exact-lcms-case-studies/ncel [Accessed: 6 Jan 2014].

[10] Almegren, A. and Yassin, S. Z. 2013. Learning Object Repositories in eLearning: Challenges for Learners in Saudi Arabia. The European Journal of Open, Distance and E-Learning, June, 26.

[11] Moussa, N. \& Moussa, S. 2009, "Quality assurance of e-learning in developing countries", Nonlinear Analysis: Theory, Methods \& Applications, vol. 71, no. 12, pp. e32-e34.

[12] Lee, S. 2013, "Technology Leadership in Saudi Higher Education", 3rd International Conference For e-learning \& Distance Education, Riyadh, Saudi Arabia.

[13] Almegren, A., Al-Yafei, A., \& Hashem, A. (2007). Pilot nationwide elearning provision in the Kingdom of Saudi Arabia: issues and challenges. 21st Asian Association of Open Universities Conference. Kuala Lumpur, Malaysia.

[14] Biloslavo, R. \& Gorela, K. 2013, 'Knowledge Management and HigherEducational Institutions: Challenges and Opportunities', Knowledge Management Innovations for Interdisciplinary Education: Organizational Applications, IGI Global, pp. 1-34

[15] Alammari, A.M. \& Chandran, D. 2013, 'The Adoption of Knowledge Management and Net Generation characteristics in E-Learning Communities in Saudi Arabia', Vision 2020: Innovation, Development Sustainability, and Economic Growth, Vienna, Austria 27-28 June 2013, June 2013 in Proceedings of the 21 st International Business Information Management Association Conference (IBIMA), ed Khalid S. Soliman, IBMA Publishing, Norristown, PA USA, pp. 818-823. 